ISSN: 0213-2060

DOI: https://doi.org/10.14201/shhme20213914568

\title{
LA REPRESENTACIÓN DOCUMENTAL DE UNA REALIDAD MATERIAL DESAPARECIDA: LA CONSTRUCCIÓN DE MONASTERIOS EN LA CIUDAD DE LEÓN (C. 1000-1050) ${ }^{1}$
}

\author{
The Documentary Representation of a Lost Material Reality: The Building of \\ Monasteries in the City of León (c. 1000-1050)
}

Gema MANCEBO GONZÁLEZ

Contratada Predoctoral IH-CSIC. Instituto de Historia. Centro de Ciencias Humanas y Sociales del CSIC. C/ Albasanz, 26-28, E-28037, MADRID. C.e: gema.mancebo@cchs.csic.es. ORCID: orcid.org/0000-0003-0281-7463

Recibido: 2021-01-14

Revisado: 2021-02-10

Aceptado: 2021-03-09

RESUMEN: Entre 1050 y 1300 se produjo una transformación en el Occidente medieval caracterizada por la proliferación de construcciones representativas en piedra. El caso de León es particular porque conserva pocos restos materiales de esta cronología, pero numerosas menciones documentales a edificios. A través de los testimonios de fundación de varios monasterios de comienzos del siglo XI se pretende reconocer si el fenómeno de la petrificación de la riqueza tuvo un inicio temprano en la ciudad. Para esto se ha hecho una revisión de quiénes fueron los fundadores, con qué recursos contaron, cuál fue la materialidad de los edificios y a qué motivaciones respondieron.

Palabras clave: Construcción; Petrificación; Monasterios; Siglo XI; León.

ABSTRACT: Between 1050 and 1300, a transformation occurred in the mediaeval west, characterized by the proliferation of representative structures in stone. The case of León is unusual because it preserves few remains from this timeframe, but numerous documented

1 Esta investigación se ha desarrollado dentro del proyecto «Petrifying Wealth. The Southern European Shift to Masonry as Collective Investment in Identity, c. 1050-1300» del CCHS-CSIC Instituto de Historia, financiado por el programa de investigación e innovación Horizonte 2020 de la Unión Europea bajo el acuerdo n. ${ }^{\circ} 695515$.

"Abreviaturas: CDACL III = Ruiz Asencio, José Manuel. Colección documental del Archivo de la Catedral de León (775-1230). Vol. III (986-1031). León: Centro de Estudios e Investigación «San Isidoro», 1987; CDACL IV = Ruiz Asencio, José Manuel. Colección documental del Archivo de la Catedral de León (775-1230). Vol. IV (1032-1109). León: Centro de Estudios e Investigación «San Isidoro», 1989. 
mentions of buildings. Through the foundation testimonies of several monasteries at the beginning of the 11 th century, the intention is to recognize whether the phenomenon of petrification of wealth had early beginnings in the city. For this purpose, a review of who the founders were, the resources they had, the materiality of the buildings and the motivations they satisfied has been carried out.

Keywords: Construction; Petrification; Monasteries; 11th century; León.

SUMARIO: 0 Introducción. 1 Construcción, transformación y destrucción en la ciudad de León. 2 Protagonistas, recursos, materialidad y causas del proceso constructivo. 3 Hacia una síntesis de los procesos constructivos de los monasterios leoneses. 4 Referencias bibliográficas.

\section{INTRODUCCIÓN}

Durante la segunda mitad del siglo xi se produjo un cambio en el paisaje del occidente cristiano, caracterizado por el aumento exponencial del número de construcciones representativas en piedra - tanto civiles como religiosas- Este proceso, que se desarrolló entre los ańos 1050 y 1300, ha sido denominado como "Petrificación de la Riqueza" y se vincula con construcciones de calidad, realizadas mediante ciclos productivos complejos y empleando materiales duraderos ${ }^{2}$. Lejos de contar con un carácter unívoco, el fenómeno se extendió por la península ibérica, la itálica y el sur de Francia, donde proliferaron diferentes tipos edilicios. En los territorios centrales de la península ibérica la petrificación se vincula con la eclosión del románico, que cuenta con amplias representaciones fechadas a partir de la segunda mitad del XI. El espacio central de León es un ejemplo singular, debido a la reducida cantidad de restos materiales conservados, que contrasta con los datos de otras zonas de los reinos de León y Castilla, como Burgos o Segovia ${ }^{3}$. Sin embargo, la documentación de la Catedral de León plantea un panorama muy diferente, puesto que recoge una elevada cantidad de menciones a edificios, distribuidos tanto por las áreas rurales como urbanas.

El desequilibrio entre los edificios conservados y los documentados es patente en una cronología muy temprana para la ciudad de León, ya que son numerosos los monasterios que aparecen en los diplomas desde finales del siglo x y comienzos del XI, momento en el que ostenta la capitalidad del reino homónimo. Estos han sido estudiados por diversos autores, como Manuel Risco en su obra sobre las iglesias y monasterios ${ }^{4}$, Claudio

2 Esta definición ha sido acuñada por el proyecto Petrifying Wealth en el transcurso de las investigaciones que están llevando a cabo. La historiografía no ha abordado estos problemas, que están siendo definidos dentro del marco del proyecto.

3 La información sobre el volumen de edificios conservados ha sido extraída de la base de datos del proyecto Petrifying Wealth que se abrirá a la consulta pública al final del proyecto y de: VV. AA. Enciclopedia del Románico en Castilla y León: León. Aguilar de Campoo: Fundación Santa María la Real, 2002.

4 Risco, Manuel. Iglesias de León y monasterios antiguos de la misma ciudad. Madrid: En la oficina de Don Blas Román, 1792. 
Sánchez-Albornoz en su trabajo sobre la urbe ${ }^{5}$ o Carlos Estepa, quien los analiza de un modo más pormenorizado, nombrado hasta una treintena de primeras menciones entre los años 1000 y $1050^{6}$. Si bien la mayoría de estas alusiones son poco elocuentes, se han conservado documentos que enuncian los procesos de construcción de los cenobios de Santa María, San Pedro y San Pablo, San Vicente, San Félix, San Miguel, San Juan Bautista, San Román y Santa Cristina. Estas fundaciones han sido abordadas recientemente por Álvaro Carvajal ${ }^{7}$ o Raúl González ${ }^{8}$ y encajan dentro del fenómeno de los monasterios propios, ampliamente estudiado en las últimas décadas ${ }^{9}$.

El dinamismo constructivo que se trasluce de los documentos no tiene correlación con las pervivencias materiales ni la arqueología. Las intervenciones sobre el suelo urbano han permitido corroborar un marcado carácter agrario - caracterizado por la pervivencia de numerosos espacios vacíos en el interior del viejo recinto ${ }^{10}$ —, pero apenas han localizado estructuras de la primera mitad del siglo $\mathrm{XI}^{11}$. Por lo tanto, los ocho monasterios mencionados constituyen una de las mayores evidencias a la hora de estudiar los procesos constructivos en León. A pesar de que no pueden identificarse con ningún resto material, estos documentos contienen información que permite comprender cuáles fueron las dinámicas de los procesos edilicios. Aun así, se debe tener en cuenta que el análisis puede estar condicionado por una cuestión de conservación y estos testimonios pudieron formar parte de una realidad mucho más amplia de la que no se tiene constancia.

La principal pretensión de este trabajo es analizar el proceso de edificación de los monasterios propios en León durante la primera mitad del siglo XI. Para este objetivo, en primer lugar, se llevará a cabo un análisis de los ocho ejemplos para determinar cuáles

5 Sánchez-Albornoz, Claudio. Una ciudad de la España cristiana hace mil años. Estampas de la vida en León. Madrid: Rialp, 1982.

6 Estepa, Carlos. Estructura social de la ciudad de León (siglos XI-XIII). Centro de Estudios e Investigación «San Isidoro». León, 1977, pp. 117-119.

7 Carvajal, Álvaro. «Un modelo (historiográfico) para armar». En García-Fernández, Miguel; Cernadas Martínez, Silvia (Coord.). Reinas e infantas en los reinos medievales ibéricos. Santiago de Compostela: Universidad de Santiago de Compostela, 2018, pp. 29-50.

8 González, Raúl. Élites urbanas y relaciones de poder en Oviedo, León y Astorga durante la Edad Media (siglos IX-XIII). Universidad de Oviedo, 2017. Tesis doctoral.

9 Algunos de los más destacados: Martínez Sopena, Pascual. «Monasterios particulares, nobleza y reforma eclesiástica en León entre los siglos XI y xII». En Ladero Quesada, Miguel Ángel; Álvarez Palenzuela, Vicente Ángel; Valdeón Baruque, Julio (Coord.). Estudios de Historia Medieval. Homenaje a Luis Suárez. Valladolid: Universidad de Valladolid, 1991, pp. 323-331; Martín Viso, Iñaki. «Monasterios y poder aristocrático». Brocar, 1996, vol. 20, pp. 91-133; García de Cortázar, José Ángel. «Monasterios hispanos en torno al año mil: función social y observancia regular». En VV. AA. Ante el milenario del reinado de Sancho el Mayor: un rey navarro para España y Europa. Pamplona: Gobierno de Navarra, 2003, pp. 213-270; Martínez Sopena, Pascual. «Aristocracias, monacato y reformas en los siglos XI y XII». VV. AA. El monacato en los reinos de León y Castilla (siglos VII-XIII). Ávila: Fundación Sánchez-Albornoz, 2007, pp. 67-100; Pérez, Mariel. «El control de lo sagrado como instrumento de poder: los monasterios particulares de la aristocracia altomedieval leonesa». Anuario de Estudios Medievales, julio-diciembre 2012, vol. 42/2, pp. 799-822; Pérez, Mariel. «Proprietary churches, episcopal authority and social relationships in the diocese of León (eleventh-twelfth centuries». Journal of Medieval Iberian Studies, 2018, vol. 10, n.o 2, pp. 195-212.

10 Estepa, Estructura social, p. 125.

11 Gutiérrez, José Avelino y Miguel, Fernando. «Génesis del urbanismo en la ciudad de León y su transformación en la Edad Media». Codex aquilarensis: Cuadernos de investigación del Monasterio de Santa María la Real, 1999, 15, p. 54. 
fueron sus particularidades y qué información pueden aportar acerca de la construcción y la materialidad de los edificios. En segundo lugar, se plantearán una serie de cuestiones acerca los implicados en estos procesos, los recursos a su disposición, la materialidad de las obras y las causas de su aparición. Asimismo, ya que esta investigación se enmarca en los estudios acerca de la petrificación de la riqueza, se busca determinar si la aparición de estos monasterios pudo estar vinculada a este fenómeno y, por lo tanto, si el proceso pudo comenzar en la ciudad de León con anterioridad a 1050.

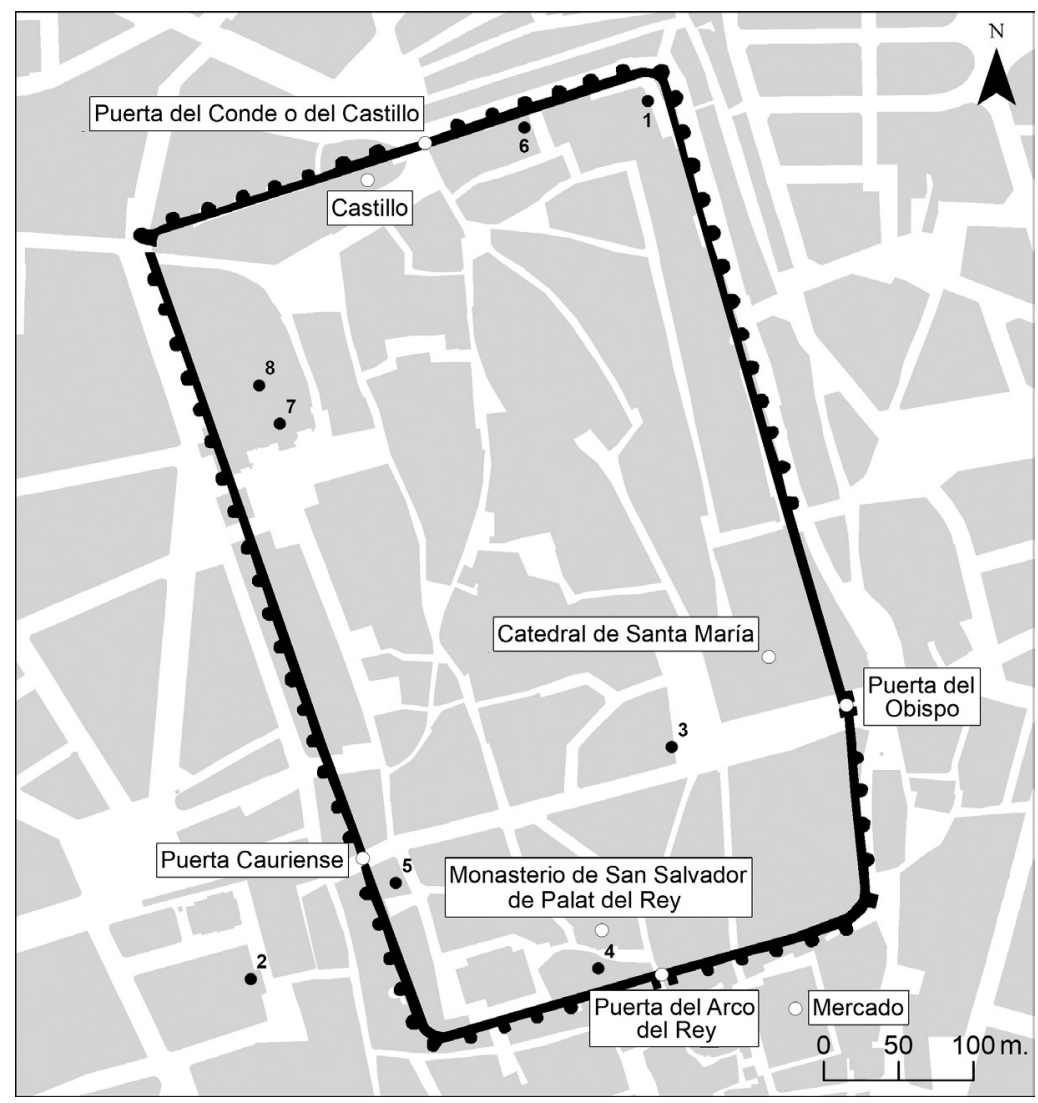

Figura 1. Mapa de la ciudad de León con la localización de los principales puntos de referencia y los monasterios tratados en el artículo ${ }^{12}: 1$. Monasterio de San Pedro y San Pablo, 2. Monasterio de San Miguel Arcángel, 3. Monasterio de San Vicente 4. Monasterio de San Juan Bautista (Munio Fernández) 5. Monasterio de San Román 6. Monasterio de Santa Marina 7. Monasterio de San Juan Bautista (San Isidoro) 8. Monasterio de San Pelayo. (Elaboración de Enrique Capdevilla Montes, IH-CSIC).

12 Los monasterios de Santa María, San Félix y Santa Cristina tienen una ubicación desconocida, por lo que no han sido incluidos en el mapa. 
LA REPRESENTACIÓN DOCUMENTAL DE UNA REALIDAD MATERIAL DESAPARECIDA:

\section{Construcción, TRANSFORMACión y DESTRUCCIÓN EN LA CIUDAD DE LEÓN}

Trabajar cuestiones materiales a través de las fuentes escritas — muchas veces parciales y fragmentarias - no es una tarea sencilla y se debe proceder siempre con cierta cautela, ya que los hechos y la forma en la que se narran pueden estar condicionados por cuestiones diplomáticas y literarias. La inclusión de proposiciones tales como construxit o edificaui ex pauimento son habituales en este periodo, sobre todo en relación con los monasterios particulares ${ }^{13}$. Además de contar con un alto carácter simbólico ${ }^{14}$, estas alusiones al proceso de edificación hacen referencia a una realidad material, es decir, a que existió una construcción física bajo esta advocación, fuera cual fuese su entidad.

Estas referencias al levantamiento de los edificios son un elemento común a todos los casos tratados, aunque no siempre alcanzan un mismo nivel de descripción ${ }^{15}$. El ejemplo del monasterio de Santa María es quizá el menos expresivo con relación a los detalles de la fábrica, ya que solo indica que este fue fundado y construido, sin precisar si quiera su ubicación exacta dentro de los muros de la urbe ${ }^{16}$. No obstante, un análisis exhaustivo de los datos conservados puede aportar más información al respecto.

Se conservan dos documentos de idéntica fecha - 18 de septiembre de $1042-y$ análogo contenido, que hacen alusión a la fundación y dotación del cenobio Santa María por la infanta Fronilde Peláez — hija del conde Pelayo Rodríguez - y su marido el infante Ordońo Bermúdez — hijo ilegítimo de Bermudo II— ${ }^{17}$. En el segundo texto Fronilde se intituló como ancilla ${ }^{18}$ y realizó las acciones ob remedium uiro meo, lo que constata el deceso de Ordońo. Esto puede significar que, en el momento de redacción de los documentos, el infante ya había fallecido y su esposa pretendía manifestar que ambos fueron promotores de la obra. El primero fue ratificado por el obispo Servando de León (1026$1040)^{19}$ y en el segundo menciona a su sucesor, Cipriano, lo que permite observar un desajuste entre la datación y los hechos expuestos. Esto plantea cierto margen temporal entre la redacción de uno y otro, al tiempo que pone de manifiesto que la fundación se puso por escrito con posterioridad a la construcción del edificio, que ya debía existir en $1042^{20}$. De hecho, un documento datado en 1038 recoge la última voluntad del presbítero Hecta de entregar sus bienes a un cenobio de Santa María, situado en la ciudad. Este

13 Orlandis, José. «Los monasterios familiares en España durante la Alta Edad Media». Anuario de Historia del Derecho Español, 1956, vol. 26, p. 20.

14 Carvajal, «Un modelo», pp. 38-39.

15 Figura 1.

16 CDACL IV, doc. 1002, doc. 1042. En su trabajo sobre la ciudad, Claudio Sánchez-Albornoz no logró situar el monasterio de Santa María. Sánchez-Albornoz, Una ciudad, p. 153.

17 CDACL IV, doc. 1002, doc. 1003.

18 Sub tuo, Domine, imperio et regni gubernaculo, ego ancilla tua Fronildi, CDACL IV, doc. 1003.

19 Posadilla, Juan de Dios. Episcopologio legionense: biografía de los obispos de León. Tomo I. León: Imp. de Maximino A. Miñón, 1899, págs. 134-154;

20 Es habitual que la escritura de fundación sea posterior a la construcción del edificio. Esto se corrobora también en los ejemplos de San Miguel y San Félix. Sobre estas discordancias: Carvajal, «Un modelo», p. 44; Carriedo Tejedo, Manuel. «Dos fraudes sincrónicos al monasterio de Celanova (en León y en Galicia) a comienzos del siglo XI». Rudesindus, 2008, vol. 4, pp. 43-62. 
fue identificado por Manuel Risco con el aquí tratado ${ }^{21}$, ya que no había ningún otro monasterio bajo esta advocación en la ciudad para esta cronología.

Son varios los miembros de la familia de Fronilde y Ordoño vinculados al monasterio, como en el caso de sus hijos-Bermudo, Sancho, Fernando y Jimena- que participaron de su fundación y dotación ${ }^{22}$. También una nieta del matrimonio, llamada Marina, fue nombrada en el primer documento como beneficiaria de Santa María, siempre y cuando profesase la vida religiosa. Sin embargo, esta no aparece de nuevo en el segundo, que deja constancia del traspaso del establecimiento religioso a la sede legionense y a su obispo Cipriano. La donación se corrobora como efectiva gracias a una de las entradas de los obituarios de la catedral, que recoge el fallecimiento de la infanta Fronilde qui dedit nobis monasterium Sancte Marie de scriptoribus, alrededor de $1058^{23}$.

Entre la fundación de Santa María y su fallecimiento casi dos décadas después, Fronilde aparece en numerosos documentos vinculados con la obtención de propiedades en diferentes lugares ${ }^{24}$. Este tipo de prácticas — común para las elites de este periodo- fue empleada por los fundadores de estos monasterios leoneses de la primera mitad del siglo XI y encajan dentro de «una activa política de adquisición de bienes patrimoniales»" ${ }^{25}$. No obstante, el ejemplo de Fronilde se caracteriza porque casi la totalidad de los solares se hallaban en la ciudad de León y porque realizó estas compras cuando el monasterio ya estaba construido. Por lo tanto, los solares no fueron empleados para la edificación, como se ha registrado en otros casos. Es probable que fuesen adquiridos con el objetivo de pasar a formar parte del patrimonio del monasterio ${ }^{26}$, ya que en el segundo texto fundacional la infanta incluyó como parte de la dotación una serie de tierras y huertos que había comprado en la ciudad. No es inusitado pensar que esta mecánica se reprodujese con las transacciones posteriores ${ }^{27}$.

El interés por la obtención de solares en la ciudad también se puede apreciar en el caso de María Velázquez, fundadora del monasterio de San Pedro y San Pablo en 1034, que llegó desde Navarra como acompañante de la reina Urraca, viuda de Alfonso $\mathrm{V}^{28}$.

21 CDACL IV, doc. 957; Risco, Iglesias de León, pp. 132-133.

22 CDACL IV, doc. 1002, doc. 1003.

23 Herrero Jiménez, Mauricio. Colección documental del Archivo de la Catedral de León: Obituarios Medievales. León: Centro de Estudios e Investigación «San Isidoro», 1994, p. 339. El año del fallecimiento ha sido extraído de: Navarro Baena, Alberto. "La memoria regia a través de los obituarios leoneses». En Arias Guillén, Fernando y Martínez Sopena, Pascual (coords.). «La memoria regia a través de los obituarios leoneses». En Arias Guillén, Fernando y Martínez Sopena, Pascual (cords.). Los espacios del rey. Poder y territorio en las monarquías hispánicas (siglos XII-XIV). Bilbao: Universidad del País Vasco, 2018, pp. 406-408.

24 CDACL IV doc. 1016, doc. 1017, doc. 1018, doc. 1019, doc. 1022, doc. 1027, doc. 1030, doc. 1044, doc. 1063 , doc. 1064 .

25 Carvajal, «Un modelo», p. 35.

26 La posible relación entre las compraventas y la dotación patrimonial de Santa María ya fue señalada por: García Álvarez, Manuel Rubén. "La infanta Fronilde, peregrina a Compostela». Compostellanum: revista de la Archidiócesis de Santiago de Compostela, 1964, vol. 9, n. ${ }^{\circ}$ 2, p. 184.

27 Et adicio adhuc ibi in Legione terras et ortos et solares que abui compratos, concedo uobis eas ab integro, CDACL IV, doc. 1003. A este respecto cabría ańadir que todos los diplomas de compraventas llevados a cabo por Fronilde han pasado a formar parte del Tumbo Legionense, lo que corroboraría su paso a la propiedad de la sede Legionense tras la anexión del cenobio de Santa María.

28 CDACL IV, doc. 924. 
El texto de fundación menciona como esta mujer había comprado varios solares por un pretio iusto para la construcción del monasterio. Estos podrían corresponderse con los situados intramuros, en las inmediaciones de la Puerta del Conde, que María adquirió mediante varias compraventas a partir de $1031^{29}$. Sin embargo, uno de estos títulos está fechado en 1035 — un año después de la escritura fundacional-y menciona al monasterio como una de las lindes ${ }^{30}$. Esto plantea ciertos interrogantes acerca de sí mediante su obtención pretendía ampliar la dotación del monasterio o, por el contrario, era necesario para concluir la construcción.

Los datos sobre la materialidad de San Pedro y San Pablo se limitan a una mención a las partes que lo integran: domos et abudecis et ecclesia ${ }^{31}$. La referencia no aporta información más detallada sobre ninguno de estos espacios, pero permite definir cuáles pudieron ser los elementos básicos constitutivos de los monasterios propios leoneses en este periodo. En este sentido, confirma un aspecto generalmente asumido como cierto: la existencia de un área de habitación para la comunidad monástica. Para este caso, se conoce a los ocupantes del cenobio gracias la disposición de María Velázquez de dejar sus bienes a Martinus Petriz cum omnes sacerdotes, confessores, cleros et ceteros ibi abitantes tras su fallecimiento.

Muchas de las características del caso de María Velázquez se corroboran para el ejemplo de doña Salomona, que aparece como fundadora de San Vicente en $1036^{32}$. Los datos que se conocen sobre esta mujer se limitan a su papel como promotora del monasterio y a su activa participación en los procesos de adquisición de inmuebles ${ }^{33}$. Se conservan varias compraventas, entre las que destaca un diploma del 1005, mediante el que obtuvo un solar dentro de la muralla, junto a la catedral de Santa María ${ }^{34}$. Si bien es cierto que el texto fundacional no hace referencia a la ubicación del cenobio, ciertos testimonios lo sitúan en la misma área intramuros ${ }^{35}$, lo que podría poner en relación la compra del solar con la construcción. Incluso se tiene constancia de su existencia varias décadas antes del texto fundacional, gracias a varias donaciones en su beneficio ${ }^{36}$. En lo tocante a la materialidad, tan solo se alude a la construcción del monasterio y una «domum» de oración ${ }^{37}$, lo que apenas aporta información sobre cual pudo ser su aspecto. Por el contrario, se aprecia un mayor interés a la hora de presentar a las ocupantes del lugar, que eran uirginum puellarum et deodigarum et multas certatrices militantes in

29 CDACL III doc. 891, doc. 892, doc. 893; CDACL IV doc. 937. El editor de los documentos señala la posible relación entre los solares adquiridos y la construcción del monasterio.

${ }_{30}$ [...] Et alia parte tramos de monasterio Sancti Petri quos edificauit ipsa Maria Uelasquiz [...], CDACL IV, doc. 937.

31 CDACL IV, doc. 924.

32 CDACL IV, doc. 946.

33 Carvajal, «Un modelo», p. 36.

34 CDACL III 646.

35 Carvajal, «Un modelo», p. 37.

36 Algunos ejemplos de donaciones al monasterio: CDACL III, doc. 689 (1010), doc. 696 (10101011).

37 Figura 2. 
Christo, siendo Columba, una sobrina de Salomona, quien tomó posesión del centro tras su fallecimiento ${ }^{38}$.

La fundación del monasterio de San Félix por el obispo Nuño de León en el 1020 presenta amplias semejanzas con los casos expuestos, como la adquisición de los solares para edificar por un pretio iusto o la voluntad de que pasasen a sus sociores et congermanas tras su deceso ${ }^{39}$. Al igual que ocurre con Santa María, se desconoce su ubicación exacta dentro de los muros de la ciudad ${ }^{40}$. Por el contrario, se tienen más datos sobre sus características edilicias, ya que se menciona la construcción de una domus mirificus ${ }^{41}$ compuesta por una corte, rodeada por un muro y con una iglesia en el centro.

Ciertos aspectos que rodean a la fundación del monasterio de San Miguel cuentan con un gran interés para el estudio de los procesos constructivos en la ciudad. Su historia es semejante a las anteriores: un presbítero llamado Félix — cuyo origen no está del todo claro, pero que aparece frecuentemente en los diplomas leoneses hasta la mitad del siglo $\mathrm{XI}$ - lo fundó extramuros, en la vega del Bernesga, junto al de San Claudio ${ }^{42}$. Sin embargo, el documento ofrece poca información sobre el proceso edilicio del cenobio. El texto de la fundación y dotación integra el relato de un conflicto acontecido entre el propio fundador y Manilán —abad de Celanova_ por el solar donde se levantó el templo que, según Félix, le había donado una mujer llamada Columba. Tras determinar que el solar pertenecía a Celanova por una donación del obispo Sisnando, se alcanzó un acuerdo por el que Félix debía construir una casa dentro de los muros y entregársela al monasterio como compensación. Para llevar a cabo este cometido, se le dieron varias pautas: debía tener las mismas dimensiones que la del fratri Teodemiro — quien ejercería como fideiussor de la obra- y estar terminada para el día de San Juan Bautista ${ }^{43}$. No es posible saber ni las medidas del edificio, ya que se desconoce por completo la entidad del inmueble que se tomó como modelo, ni el tiempo que ocupó la obra. Aun así, el hecho de que se establezcan instrucciones tan específicas puede indicar la existencia de cierta estandarización en los procesos de construcción. Si bien es cierto que la amplitud de realidades recogidas bajo el término kasa dificulta el reconocimiento del aspecto y la función que pudo tener el edificio construido por Félix. Es probable que este lugar cumpliese la función de una casa monástica, debido a su pertenencia a una institución religiosa como el monasterio de Celanova ${ }^{44}$, pero no se conserva información que lo corrobore.

Hasta ahora se ha podido comprobar que hay ciertos patrones comunes en el modo en que las fuentes diplomáticas reflejan la construcción. Salvando las singularidades de

38 CDACL IV, doc. 946.

39 CDALC III, doc. 770.

40 Claudio Sánchez-Albornoz tampoco clarifica la situación del monasterio de San Félix. SánchezAlbornoz, Una ciudad, p. 153.

41 El término domus presenta una notable polisemia, ya que puede hacer referencia a edificios genéricos, iglesias, palacios, monasterios u hospitales, lo que complejiza la aproximación a una realidad material. Pérez, Maurilio (Ed.). Lexicon Latinatis Medii Aevi Regni Legionis (s. VIII-1230). Imperfectvm. Turnhout: Brepols, 2010, pp. 258-9.

42 CDACL III, doc. 777

43 CDACL III, doc. 777.

44 Carvajal, «Un modelo», p. 37. 
LA REPRESENTACIÓN DOCUMENTAL DE UNA REALIDAD MATERIAL DESAPARECIDA: LA CONSTRUCCIÓN DE MONASTERIOS EN LA CIUDAD DE LEÓN (CA. 1000-1050) GEMA MANCEBO GONZÁLEZ

cada caso, todos explican el proceso de edificación de los monasterios de una manera lineal: presentación de los fundadores, adquisición del terreno, referencia al propio acto constructivo y, en algunos casos, posterior donación. Sin embargo, la documentación contiene ciertos ejemplos en los que la intención inicial no era construir un cenobio y se produjo una transformación de estructuras preexistentes.

Dentro de este marco se sitúa el testimonio de la fundación de San Juan Bautista del 1011, por el conde Munio Fernández —individuo con una posición destacada en el reino, que había tomado parte en hasta dos ocasiones de levantamientos contra los monarcas- y su segunda esposa, Elvira ${ }^{45}$. En las primeras décadas del siglo XI, el matrimonio adquirió un solar por pretio iusto situado junto a la Puerta del Arco y a San Salvador, que incluía dos torres del muro de la ciudad. En este lugar, los condes construyeron una casa grande, con sobrados, bodegas y una corte rodeada por un muro. Una vez terminada la obra, decidieron convertir una de las torres en una domus orationis, en la que situaron dos altares bajo los que colocaron reliquias del Lignum Crucis, de San Pedro y San Pablo y de San Juan Bautista; además, fundaron en el lugar otra iglesia dedicada a Santa María. El texto menciona también la consagración por parte del obispo Nuño, lo que se puede poner en relación con las reliquias, puesto que ambos son aspectos característicos del proceso de dedicación de iglesias en la Alta Edad Media ${ }^{46}$.

Resulta interesante observar cómo este texto enumera las áreas del complejo palacial: zona de hábitat, espacios de almacenaje y una corte. Esta información ayuda a entender cuál podía ser la entidad real de un palacio nobiliario y abre vías para analizar sus funciones. Por otro lado, la transformación de la torre en un centro religioso plantea otra perspectiva para el estudio de los edificios leoneses, puesto que supone la reconversión de ciertos elementos preexistentes dotándolos de un nuevo carácter. Por último, no se aprecian con claridad qué dependencias conformaron el monasterio. El conde Munio y Elvira lo donaron a Teresa, deodicata, y a su comunidad de religiosas, pero sin aclarar si esto incluía tan solo la torre reconvertida — que haría las veces de espacio de culto y casa monástica- o también alguno más de los inmuebles del solar. Las menciones posteriores no ayudan a resolver esta incógnita, puesto que lo único que se conoce es que Fernando I confiscó San Juan Bautista al conde Flaín Fernández en represión a su insubordinación y lo entregó a la infanta Urraca ${ }^{47}$.

La fundación del monasterio de San Román, reflejada en un documento de $1047^{48}$, presenta paralelismos con lo expuesto. Sus artífices fueron el conde Ansur Díaz de Carrión, perteneciente al linaje de los Banu Gómez, y su segunda mujer, Justa Fernández, vinculada a la parentela de los Flaínez ${ }^{49}$. El matrimonio quería construir una vivienda en

45 CDACL III, doc. 701. Para ampliar: Martínez Sopena, Pascual. La Tierra de Campos occidental: poblamiento, poder y comunidad del siglo X al XIII. Valladolid: Institución Cultural Simancas, 1985, pp. 337341 .

46 Gallart, Pascual. "El ritual de la dedicación de la iglesia en los pontificales medievales y su ciclo icónico». IMAGO Revista de Emblemática y Cultura Visual, 2013, vol. 5, pp. 79-89.

47 Martínez Sopena, Pascual. «Prolis Flainiz. Las relaciones familiares en la nobleza de León». Studia Zamoranensia, 2018, vol. XVII, pp. 82-83.

48 CDACL IV, doc. 1047.

49 Martínez Sopena, "Prolis Flainiz», pp. 81-82. 
León, motivo por el cual hizo una petición a los reyes - Fernando I y Sancha- para que les concediesen un solar; les fue entregado uno junto a la Puerta Cauriense, que incluía algunas de las torres de la muralla, donde hicieron unos palacios. Posteriormente, Ansur y Justa crearon en el citado lugar una domus orationis dedicada a San Román y la entregaron a la catedral, pero estipularon que el diácono Lázaro la tendría hasta su muerte. Los márgenes temporales en los que se enmarcan los acontecimientos no son definidos en el documento, pero puede intuirse que todas estas acciones tuvieron lugar en un lapso temporal transcurrido entre el inicio del reinado de Fernando I en 1037 y la muerte de Ansur, alrededor de $1048^{50}$.

Este testimonio cuenta con algunos aspectos ya presentes en el ejemplo de San Juan: la referencia a un solar que integra parte del lienzo murario, la intención inicial de levantar una obra civil y el posterior deseo de edificar un centro religioso. Sin embargo, la sobriedad de la descripción del proceso constructivo no permite entender cuál fue la interrelación entre los elementos: ¿̨fueron las torres amortizadas para alguna de las construcciones? ¿La obra del monasterio se realizó ex novo o aprovechó partes del complejo anterior? No hay datos suficientes para llevar la cuestión de las transformaciones más allá del terreno de la hipótesis.

De hecho, existe un segundo documento en el que se resuelve un pleito entre Lázaro Peláez y García Osórez —este último, en representación de los intereses del monasterio de Santiago- por la posesión de unos solares quos fabrigauerat Asur Didaz in diebus suis $^{51}$. La ubicación de estos no está del todo clara, debido a que la deficiente conservación del documento ha ocasionado la pérdida parcial del contenido; tan solo se sabe que estaba cerca del término de Santiago, del muro y de una de las puertas ${ }^{52}$. Uno de los elementos ilegibles es, precisamente, el nombre de este acceso a la ciudad, por lo que no se puede asegurar que sea la Cauriense. Además, que el litigante se llame Lázaro, como el diácono que recibió San Román de parte de Ansur, puede ser un buen indicio para identificar los solares con los del documento $1047^{53}$. Aun así, la única alusión a la existencia de construcciones en el solar se limita al ya mencionado término fabrigaberunt, sin precisar si se trataba de los palacios o el monasterio. El conflicto se saldó con la entrega por parte de Lázaro de un pago de 150 sueldos, que iban a ser dedicados a la obra del monasterio de Santiago, que estaba destruido ${ }^{54}$.

Más allá de su posible filiación a San Román, este diploma plantea otro tema de interés: el del estado de ruina en el que parecían encontrarse algunos de los edificios monásticos de la ciudad de León durante la primera mitad del siglo XI. El texto más significativo a este respecto es uno del año 1023, que relata como Santa Cristina fue destruido como consecuencia de las incursiones musulmanas de finales del siglo x. Este monasterio había sido fundado por Arias y Baldredo — padre e hijo— para albergar a las mujeres de

50 Su defunción se menciona en: CDACL IV, doc. 1057.

51 CDACL IV, doc. 1057.

52 El editor del documento interpreta termino Sancti Iacobi con la ubicación del monasterio, pero parece posible que se refiera a un terreno propiedad del monasterio.

53 González, Élites, p. 682.

54 [...] in restauratione de illa eglesie Sancti Iacobi, quia iam dextructa erat [...], CDACL, doc. 1057. 
su familia y para servir como panteón familiar. Los ataques a la ciudad tuvieron como consecuencia el cautiverio de esta comunidad femenina que, a su regreso, encontró el cenobio distructum et dimersum in terra y non potuerunt edificare in ciuis Legione abitacu$\operatorname{lum}^{55}$. La inexistencia de restos materiales y el absoluto desconocimiento de la ubicación del monasterio imposibilitan discernir el alcance real de estos procesos destructivos. Los hechos son narrados por Flora, nieta del fundador de Santa Cristina, que los incluyó en un documento de donación de sus bienes al monasterio de Santiago de León, donde era abadesa $^{56}$. Este testimonio también incorpora una dramática narración sobre el estado de ruina en el que se encontraba León tras las incursiones musulmanas:

[...] Et proiecerunt ciuitates in terra, destruxerunt parietes et nos posuerunt in conculcatione; ciuitates dimiserunt in pavimento, capita hominum truncauerunt, in gladio percutere ut non ciuem, non uicus, non kastellis, eis non remasit ad eius deuastatione [... $]^{57}$.

De hecho, este tipo de relatos, muchas veces cargados de fuertes componentes literarios están presentes tanto en diplomas coetáneos ${ }^{58}$, como en los textos cronísti$\cos ^{59}$. Esto plantea una cuestión acerca de si estas narraciones deben ser interpretadas de manera literal — si hubo realmente destrucciones — o se trata de formulismos diplomáticos.

\begin{tabular}{|c|c|c|c|c|c|}
\hline Edificio & Fundador & $\begin{array}{l}\text { Documento } \\
\text { de fundación }\end{array}$ & $\begin{array}{c}\text { Fecha de } \\
\text { documento* }\end{array}$ & $\begin{array}{l}\text { Referencia al proceso } \\
\text { de construcción }\end{array}$ & $\begin{array}{l}\text { Adquisición } \\
\text { del solar }\end{array}$ \\
\hline $\begin{array}{l}\text { Monasterio } \\
\text { de San Juan } \\
\text { Bautista }\end{array}$ & $\begin{array}{l}\text { Conde } \\
\text { Munio } \\
\text { Fernández y } \\
\text { Elvira }\end{array}$ & $\begin{array}{l}\text { CDACL III, } \\
\text { doc. } 701\end{array}$ & 1011 & $\begin{array}{l}\text { "[...] et cum Dei adiuto- } \\
\text { rium ereximus ibidem a } \\
\text { pauimento [...]". } \\
\text { "[...] edificare ecclesiam } \\
\text { pro animas nostras [...]". }\end{array}$ & Compra \\
\hline $\begin{array}{l}\text { Monasterio } \\
\text { de San Félix }\end{array}$ & $\begin{array}{l}\text { Obispo } \\
\text { Nuño }\end{array}$ & $\begin{array}{l}\text { CDACL III, } \\
\text { doc. } 770\end{array}$ & $1020^{*}$ & $\begin{array}{l}\text { "[...] ubi edificaui domus } \\
\text { mirificus et cortem clausa } \\
\text { per circuitu et in medio } \\
\text { erexi ex pauimento eccle- } \\
\text { siam in honorem Sancti } \\
\text { Felicis [...]". }\end{array}$ & Compra \\
\hline $\begin{array}{l}\text { Monasterio } \\
\text { de San } \\
\text { Miguel de } \\
\text { Vega }\end{array}$ & $\begin{array}{l}\text { Presbítero } \\
\text { Félix }\end{array}$ & $\begin{array}{l}\text { CDACL III, } \\
\text { doc. } 777\end{array}$ & $1029^{*}$ & $\begin{array}{l}\text { "Postquam a pauimento } \\
\text { hunc domun erexi [...]". }\end{array}$ & Donación \\
\hline
\end{tabular}

55 CDACL III, doc. 803.

56 Para más información: Carvajal, «Un modelo», pp. 41-42.

57 CDACL III, doc. 803.

58 A modo de ejemplo, una donación de 1012 al monasterio de los Santos Justo y Pastor de Ardón refleja un marco de destrucción semejante: CDACL III, doc. 706.

59 La perpetración de estas destrucciones está presente en la Crónica Silense: [...] Devastavit quidem civitates, castella, omnemque terram depopulavit [...], Santos Coco, Francisco. Historia Silense. Madrid: Sucesores de Rivadeneyra, 1921, p. 58. 
LA REPRESENTACIÓN DOCUMENTAL DE UNA REALIDAD MATERIAL DESAPARECIDA: LA CONSTRUCCIÓN DE MONASTERIOS EN LA CIUDAD DE LEÓN (CA. 1000-1050) GEMA MANCEBO GONZÁLEZ

\begin{tabular}{|c|c|c|c|c|c|}
\hline Edificio & Fundador & $\begin{array}{l}\text { Documento } \\
\text { de fundación }\end{array}$ & $\begin{array}{c}\text { Fecha de } \\
\text { documento* }\end{array}$ & $\begin{array}{l}\text { Referencia al proceso } \\
\text { de construcción }\end{array}$ & $\begin{array}{l}\text { Adquisición } \\
\text { del solar }\end{array}$ \\
\hline $\begin{array}{l}\text { Monasterio } \\
\text { de Santa } \\
\text { Cristina }\end{array}$ & $\begin{array}{l}\text { Arias y } \\
\text { Baldredo }\end{array}$ & $\begin{array}{l}\text { CDACL III, } \\
\text { doc. } 803\end{array}$ & $1023^{*}$ & $\begin{array}{l}\text { "[...] eo quod edificauit } \\
\text { Arias et filii sui Baldredo } \\
\text { monasterium uocabulo } \\
\text { Sancte Christine [...]". }\end{array}$ & Desconocida \\
\hline $\begin{array}{l}\text { Monasterio } \\
\text { de San Pedro } \\
\text { y San Pablo }\end{array}$ & $\begin{array}{l}\text { María } \\
\text { Velázquez }\end{array}$ & $\begin{array}{l}\text { CDACL IV, } \\
\text { doc. } 924\end{array}$ & 1034 & $\begin{array}{l}\text { "[...] construxi in illum } \\
\text { arcisterium ex pauimento } \\
\text { cum domos et abudecis et } \\
\text { ecclesia a manibus meis } \\
\text { fundata [...]". }\end{array}$ & Compra \\
\hline $\begin{array}{l}\text { Monasterio } \\
\text { de San } \\
\text { Vicente }\end{array}$ & Salomona & $\begin{array}{l}\text { CDACL IV, } \\
\text { doc. } 946\end{array}$ & 1036 & $\begin{array}{l}\text { "[...] edificaui ex pani- } \\
\text { mento arcisterium et do- } \\
\text { mum orationis }[\ldots] " \text {. }\end{array}$ & Compra \\
\hline $\begin{array}{l}\text { Monasterio } \\
\text { de Santa } \\
\text { María }\end{array}$ & $\begin{array}{l}\text { Infantes } \\
\text { Fronilde } \\
\text { Peláez y } \\
\text { Ordoño } \\
\text { Vermúdez } \\
\end{array}$ & $\begin{array}{l}\text { CDACL IV, } \\
\text { doc. } 1002\end{array}$ & $1042^{*}$ & $\begin{array}{l}\text { "[...] ad fundamine dinos- } \\
\text { citur esse constructum loco } \\
\text { predicto ciuitate et sede Le- } \\
\text { gione }[\ldots] \rrbracket .\end{array}$ & Desconocida \\
\hline $\begin{array}{l}\text { Monasterio } \\
\text { de San } \\
\text { Román }\end{array}$ & $\begin{array}{l}\text { Conde } \\
\text { Ansur Díaz } \\
\text { y Justa }\end{array}$ & $\begin{array}{l}\text { CDACL IV, } \\
\text { doc. } 1047\end{array}$ & 1047 & $\begin{array}{l}\text { "[...]edificare in ipso loco } \\
\text { arcisterium et domus ora- } \\
\text { tionis [...]". }\end{array}$ & $\begin{array}{l}\text { Donación } \\
\text { regia }\end{array}$ \\
\hline
\end{tabular}

* Las fechas que incluyen asterisco $\left(^{*}\right)$ reflejan que el momento de construcción del edificio es anterior a la creación del documento.

Figura 2. Características de los casos de estudio (Elaboración propia a través de los documentos).

\section{Protagonistas, Recursos, MATERIALIDAd y CAUSAS DEL PROCESO CONSTRUCTIVo}

La primera cuestión versa en torno a la identificación de los individuos involucrados en los procesos de construcción de estos monasterios leoneses ${ }^{60}$. Los testimonios analizados dejan claro que el rol de los personajes se corresponde con el de fundadores y receptores de las obras, omitiendo por completo cualquier tipo de alusión a maestros de obras, artesanos u operarios. Entre los individuos mencionados, se pueden atisbar diversos tipos de involucrados de manera directa o indirecta: promotores y receptores de monasterios, participantes en transacciones de solares, litigantes por su construcción, etc.

Los principales implicados en la evolución edilicia y, por tanto, los que aportan un mayor volumen de información son los fundadores ${ }^{61}$. Por un lado, aparecen miembros

${ }^{60}$ Una aproximación inicial debería realizarse desde el concepto de makers, postulado por Therese Martin, que aplica una categorización neutral a los actores hasta el momento en que se puede identificar su género o papel en la obra. Martin, Therese. "The margin to act: a framework of investigation for women's (and men's) medieval art-making». Journal of Medieval History, 2016, 42:1, p. 5.

61 Carvajal, «Un modelo», p. 33. 
de los grupos más elevados de la sociedad y con una estrecha vinculación a los monarcas, como en el caso de los infantes Fronilde y Ordoño, o en el de María Velázquez —acompañante de la reina-; así como en los de Munio Fernández, Elvira, Ansur Díaz o Justa Fernández, donde la dignidad condal avala la proximidad al rey ${ }^{62}$. Por otro lado, integrantes del clero, como el obispo Nuño, el presbítero Félix o Salomona, estos últimos de dudoso origen, pero que terminan por convertirse en abades con destacadas posiciones en la ciudad durante estos decenios. Queda de manifiesto que existía una imbricación entre los representantes de la institución eclesiástica y las élites laicas, por lo que la diferenciación entre los integrantes de una y otra no es clara ${ }^{63}$.

Se constata también un equilibrio entre las fundaciones promovidas por mujeres y las auspiciadas por hombres, lo que pone de relieve que ambos géneros ocuparon las mismas posiciones elitistas y participaron de manera activa en los procesos de construcción de la ciudad ${ }^{64}$. Asimismo, se observa cómo estas iniciativas fundacionales encajan dentro de un esquema en el que prima un «carácter individual o conyugal, en la que no parecen estar implicados los hijos, ni muchos menos, los parientes colaterales» ${ }^{65}$. El único caso en el que no se aplica esta norma es en el del monasterio de Santa María, ya que junto al matrimonio aparecen sus hijos como fundadores.

Entre los demás personajes involucrados con estos centros, cabe mencionar la gran heterogeneidad de situaciones en las que aparecen los receptores en los documentos. En algunos casos se registran donaciones a miembros de la familia, como Marina, nieta de los infantes Fronilde y Ordoño; Columba, sobrina de Salomona o Flora, descendiente de los fundadores de Santa Cristina. Generalmente estas concesiones estaban sujetas a la permanencia en la vida religiosa de estas mujeres, cuyo papel quizá pueda relacionarse con el de la figura de la domina, ejerciendo la defensa de los intereses de la familia y actuando como intermediarias entre el monasterio y el exterior ${ }^{66}$. Los ejemplos corroboran que, aunque las iniciativas detrás de los cenobios no involucrasen a todos los miembros de la parentela, existía cierta vinculación entre ésta y el edificio ya que, al fin y al cabo, era parte conformadora de su patrimonio. No obstante, era una práctica habitual que cada generación construyese su propio monasterio, como una manera de confirmar su estatus ${ }^{67}$.

En otros casos, los receptores eran los integrantes de la propia comunidad monástica, tal como sucede con Munio Fernández y Elvira, que lo entregaron a la abadesa Teresa; María Velázquez, que lo donó a Martín Pétriz y el resto de la congregación, o el obispo

62 Sobre la vinculación del título condal y la monarquía: Martínez Sopena, Pascual. «Reyes y nobles en León (ca. 860-1160)». En VV. AA. Monarquía y sociedad en el Reino de León. De Alfonso III a Alfonso VII. León: Centro de Estudios e Investigación «San Isidoro», 2007, p. 183.

63 Estepa, Estructura social, p. 214.

64 Sobre el papel de las mujeres en la promoción artística véase: Martin, "The margin to act», pp. 1-25; Martin, Therese. «Exceptions and Assumptions: Women in Medieval Art History». En Martin, Therese (Ed.). Reassessing the Roles of Women as 'Makers' of Medieval Art and Architecture. Leiden-Boston: Brill, 2012, pp. $1-33$.

65 Pérez, «El control de lo sagrado», p. 805.

66 Martínez Sopena, «Monasterios particulares», pp. 327-328.

67 Pérez, «El control de lo sagrado», pp. 817-818. 
Nuño, que lo dio a las religiosas Onega y Goda ${ }^{68}$. Por último, ejemplos donde la relación entre el receptor y el donante no es tan evidente, como en el caso del diácono Lázaro, que recibió San Román de Ansur Díaz. Parece plausible que estos receptores obtuviesen, de algún modo, el control sobre la materialidad del edificio, aunque esta quedase limitada a la duración de sus vidas ${ }^{69}$. Si bien no es posible determinar el papel que desempeñaron con respecto al monasterio o si realmente pudieron ser considerados propietarios, ya que muchos de los centros pasaron a formar parte del patrimonio de la Catedral de León en el siglo $\mathrm{XI}^{70}$.

La segunda cuestión se centra en los recursos destinados a la fundación de estos monasterios. En todos los ejemplos queda de manifiesto la capacidad de los fundadores de dotar sus creaciones con bienes de diversa tipología - tierras, derechos, bienes muebles, etc.- , para conformar el patrimonio de estas instituciones ${ }^{71}$. Gran parte de los documentos analizados incorporan listados de bienes muebles que incluyen objetos litúrgicos, libros, piezas textiles, artículos de uso cotidiano, etc. ${ }^{72}$ La capacidad de abastecer a sus creaciones con este tipo de piezas de calidad constituye un indicador del alto nivel de riqueza de estos individuos ${ }^{73}$. Sin embargo, estos datos presentan una escasa utilidad a la hora de estimar los costes directos derivados de las obras de los edificios.

La información que se puede extraer de estos documentos en relación con la inversión para la construcción viene dada por las invocaciones a los procesos de adquisición de los solares para el levantamiento de los edificios. Los textos fundacionales de San Pedro y San Pablo, San Félix, San Juan Bautista y San Vicente incluyen una mención explícita al pago de un pretio iusto ${ }^{74}$ por el terreno. El valor pecuniario de estas transacciones tan solo podría estimarse para el ejemplo de San Pedro y San Pablo, para el que se han rastreado varios diplomas que recogen las compraventas llevadas a cabo por María Velázquez, que

68 Raúl González afirma que estas mujeres eran primas del obispo Nuño: González, Élites, p. 610.

69 Este tipo de propiedad no debe confundirse con la que tenían todos los miembros de la parentela que, como herederos, poseían derechos a porciones virtuales del conjunto de propiedades que integraba el patrimonio del monasterio. Martínez Sopena, «Monasterios particulares», pp. 325-326.

70 Cavero Domínguez, Gregoria. «Organización eclesiástica de las civitates episcopales de León y Astorga (siglo x)». En V.V.A.A. Iglesia y ciudad. Espacio y poder (siglos VIII-XIII). Oviedo-León: Universidad de Oviedo-Universidad de León-Instituto de Estudios Medievales, 2011, p. 91.

${ }^{71}$ Feller, Laurent. "Introduction: Formes et fonctions de la richesse des élites au Haut Moyen Âge». En Devroey, Jean-Pierre; Feller, Laurent; Le Jan, Régine (Dir.). Les élites et la richesse au Haut Moyen Age. Turnhout: Brepols, 2011, p. 7.

${ }_{72}$ Los bienes que María Velázquez entrega para la fundación de San Pedro y San Pable son los siguientes: [...] concedo ibidem de seruitium de mensa, uaso uno argenteo, culiares duas et uno trulone; et seruitium de ecclesia calice argenteo cum sua patena, turibulum ereum, libros duos ordinos; de uestimenta de ecclesia, frontales duos, kasulla grecisca cum sua adalmatica, conco et aquamanile et kampana; lecto pallio uno et alio laneo et utensilia intrinsecus domorum, cubas, mensas, cathedras, torculare uno, villas ad seruiendum, CDACL IV, doc. 924.

73 Davies, Wendy. "Notions of Wealth in The Charters of Ninth- and Tenth-Century Christian Iberia». En Devroey, Jean-Pierre; Feller, Laurent; Le Jan, Régine (Dir.). Les élites et la richesse au Haut Moyen Age. Turnhout: Brepols, 2011, pp. 268-269.

74 Clausula común en la diplomacia altomedieval, que implica la tasación de los bienes en cuestión de un valor otorgado subjetivamente por los participantes en la transacción, y no de un precio fijado objetivamente. Davies, «Notions of Wealth», pp. 277-278. 
podrían estar en relación con la construcción del edificio. Menos evidente resulta el caso de doña Salomona, que adquirió una corte en la zona del monasterio. Que se trate de una corte y no de un solar plantea una cuestión de difícil solución, acerca de si los aprovechamientos de cada uno de estos espacios pudieron ser los mismos ${ }^{75}$. Si bien es cierto que estas referencias al precio de cada solar no deben ser tomadas como algo absoluto, ya que se desconocen las dimensiones, características y elementos particulares de cada uno de ellos.

El otro mecanismo de adquisición de solares consiste en las donaciones por parte de terceros, es decir, de individuos no involucrados directamente en los procesos de construcción. Esto es lo que ocurre en el caso del presbítero Félix que, por un lado, recibió de una mujer llamada Columba una tierra para construir el monasterio de San Miguel y, por el otro, recibió de Teodemiro el solar para construir la casa de Celanova ${ }^{76}$. Más sugestivo aún es el ejemplo de Ansur Díaz, que solicitó al monarca un solar en la ciudad para edificar sus palacios y, posteriormente, el monasterio de San Román. Si bien este último ejemplo no aporta información acerca de cuál pudo ser el coste del solar, pone de manifiesto el valor simbólico de recibir una dádiva del monarca.

Esta última idea remite a otra cuestión en torno al valor de estas construcciones, como es la relevancia simbólica de los lugares escogidos para su asentamiento. La ubicación de la mayoría de estos solares se corresponde con las áreas de mayor desarrollo en la ciudad para estos siglos - el entorno de San Salvador, la Catedral o la Puerta del Obispo- ${ }^{77}$. Además, las descripciones de su ubicación incluyen menciones a su situación respecto a los muros y a los grandes hitos de la ciudad, como por ejemplo en el caso de San Pedro y San Pablo, donde se mencionan el castillo, la Puerta del Conde y la Catedral. Todo esto se relaciona con un deseo de representarse simbólicamente junto al poder ${ }^{78}$.

La tercera cuestión para comprender el proceso de construcción de estos monasterios es la de la materialidad. Como ha podido observarse, no se conservan restos que puedan adscribirse a ninguno de los casos y los documentos no hacen alusión alguna a los materiales empleados en las obras. No obstante, algunos de los testimonios aportan ciertas pistas acerca de las características de los edificios, como en el ejemplo de San Pedro y San Pablo, en el que se mencionan espacios de hábitat, almacenaje y una iglesia; o el de San Félix, donde se habla de una domus y una corte rodeadas por un muro. Aunque estas referencias procedan únicamente de dos de los casos, la simpleza de las características descritas podría llevar a pensar que se trata de elementos comunes al resto. La existencia de una zona de habitación sería necesaria para albergar a la comunidad religiosa, así como la vigencia de un espacio para la celebración del culto, independientemente de su entidad. La inclusión de espacios de almacenaje y de una corte podrían encajar como parte integradora de una economía dominical ${ }^{79}$. Todos estos elementos son compatibles con el tipo de bienes con los que se dota al monasterio, que oscilan desde elementos litúrgicos

75 Para una definición del término véase: Álvarez Maurín, María del Pilar. Diplomática asturleonesa. Terminología toponímica. León: Universidad de León, 1994, pp. 306-308.

76 Sobre la donación del segundo solar véase: Estepa, Estructura social, pp. 208-209.

77 González, Élites, pp. 256-259.

78 Carvajal, «Un modelo», pp. 36-37.

79 Cavero Domínguez, Gregoria. «Organización eclesiástica», p. 88. 
hasta el ajuar doméstico. Además, que el recinto se encuentre delimitado por muros, indica que existe un área alrededor del centro monástico, característica común para los templos prerrománicos ${ }^{80}$.

Esta información permite trazar un bosquejo ideal de las partes integradoras de estos monasterios, pero no posibilita conocer cuál sería el aspecto de los diferentes elementos — dimensiones, morfología, compartimentación, ornamentación, etc.—. Son interesantes los datos procedentes de las intervenciones arqueológicas en edificios que han sido identificados como monasterios de este periodo. Cabe mencionar el caso de San Salvador de Palat del Rey, un complejo palacial promovido por Ramiro II en el siglo x, cuya conversión en monasterio se constata para el siglo $\mathrm{XI}^{81}$. Sin embargo, su origen áulico lo dota de un carácter monumental menos probable en los casos objeto de este estudio ${ }^{82}$. En cambio, resultan de gran interés los restos que han sido identificados con Santa Marina, uno de esos monasterios propios ${ }^{83}$. Emplazado junto al muro de la ciudad, se trataba de una «sólida edificación cuadrangular (7 m de longitud por 11 de anchura), con muros de buena fábrica de mampostería y cimientos trabados con argamasa, que podrían corresponder a la iglesia o a la casa monástica» ${ }^{84}$.

De todos modos, no puede hablarse de patrones constructivos a través de un único vestigio material. Existe una gran indefinición en lo que respecta a las formas que podía adoptar un centro monástico en este periodo, pudiendo consistir en sencillos oratorios integrados en viviendas, suficientes para responder a las necesidades de una comunidad reducida, donde la presencia de un altar bastaría para convertir espacios domésticos en monasterios particulares ${ }^{85}$. Aunque no se conserve ninguna referencia que lo refrende, no sería inusitado pensar que la casa que el presbítero Félix construyó para Celanova precisamente cumpliera la función de monasterio. Asimismo, la mención a los altares de San Juan Bautista como parte del relato de conversión de una de las torres de la muralla en espacio religioso, plantea la transformación, al menos funcional, de edificios preexistentes.

El reaprovechamiento de elementos constructivos del pasado — como, por ejemplo, de la estructura muraria- parece ser un aspecto asumido ${ }^{86}$, aunque la falta de conservación no permite conocer su alcance. En este sentido, no sería inverosímil suponer que en los casos de San Juan Bautista y San Román se produjese una reconversión de los edificios palaciales en dependencias vinculadas al centro monástico. Lejos de la imagen que se

80 Bango Torviso, Isidro G. «La vieja liturgia hispana y la interpretación del templo prerrománico». En VII Semana de Estudios Medievales. Logrońo: Instituto de Estudios Riojanos, 1997, pp. 64-69.

${ }^{81}$ Cavero, "Organización eclesiástica», pp. 79-80.

82 Gutiérrez, José Avelino. «Las fuentes arqueológicas informadoras del espacio urbano medieval: la ciudad de León como ejemplo». En Solórzano Telechea, Jesús Ángel; Arízaga Bolumburu, Beatriz (Coords.) El espacio urbano en la Europa Medieval. Nájera. Encuentros internacionales del Medievo. Logrońo: Instituto de Estudios Riojanos, 2006, p. 103.

83 CDACL IV, doc. 901.

84 Gutiérrez, «Las fuentes arqueológicas», p. 102.

85 Gutiérrez; Miguel, "Génesis del urbanismo», p. 62.

86 Cosmen, María Concepción. «Noticias sobre la reconstrucción arquitectónica en la Diócesis de León durante el siglo X». Delisau Jorge, María de los Ángeles; Rodríguez Padilla, Marta; Pueyo Abril, Javier (Coords). La multiculturalidad en las Artes y en la Arquitectura: XVI Congreso Nacional de Historia del Arte. Vol. 1. Las Palmas de Gran Canaria: Anroart Ediciones, 2006, p. 603. 
LA REPRESENTACIÓN DOCUMENTAL DE UNA REALIDAD MATERIAL DESAPARECIDA:

tendrá de los palatia a partir del siglo XII, construcciones de representación dotadas de cierta monumentalidad ${ }^{87}$, los ejemplos altomedievales se caracterizan por su gran indefinición ${ }^{88}$. No obstante, se tiene constancia de que presentaban «una estructura de nivel superior al resto, con una edilicia más cuidada, que podría integrar otras construcciones con funciones específicas» ${ }^{89}$. Esto se corresponde con la imagen evocada por Munio Fernández, que habla de espacios de almacenaje y de una domus magnis ${ }^{0}$. Estos elementos parecen compatibles con las dependencias de un centro monástico, por lo que la amortización de las estructuras del complejo para su transformación es plausible.

Ahora bien, esta cuestión parece menos sencilla de clarificar para el caso de San Román, puesto que las descripciones de las partes del complejo y sus procesos edilicios son exiguas. Tampoco queda tan claro su carácter monumental, pues el documento del conflicto entre Lázaro y García hace referencia al término fabrigauerunt, que no aporta ninguna percepción acerca del empaque que pudieron tener estas obras. Sin embargo, hay que tener en cuenta que esta información procede de un documento que, además de encontrarse en un pésimo estado de conservación, refleja un conflicto con el destacado cenobio de Santiago ${ }^{91}$, por lo que la omisión a la posible existencia del monasterio de San Román podría no ser inocente. Lo único que queda claro gracias al pleito es la existencia de unas construcciones indefinidas que se ubican en un solar de dimensiones desconocidas, lo que no permite saber si varias construcciones de cierta entidad podrían convivir en un mismo espacio.

Por último, cabría preguntarse cuáles fueron las causas que condujeron a la aparición y desaparición de estas construcciones. Algunas de las motivaciones aportadas por los autores que han tratado el fenómeno de los monasterios propios los sitúan como formas de articular el prestigio social y religioso ${ }^{92}$; modo de representarse junto al poder en la capital ${ }^{93}$, parte de una organización dominial ${ }^{94}$, un medio para asegurar el patrimonio familiar ${ }^{95}$ e, incluso, una vía para la salvación de las almas ${ }^{96}$. Todas ellas parecen estar

87 Martin, Therese. "Chronicling the Iberian Palace: written sources and the meaning of medieval Christian rulers' residences». Journal of Medieval Iberian Studies, 2010, vol. 2, n.o 1, pp. 109-139.

88 García de Cortázar, José Ángel; Peña Bocos, Esther. «El Palatium, símbolo y centro de poder, en los reinos de Navarra y Castilla en los siglos x a XII». Mayurqa: revista del Departament de Ciències Històriques $i$ Teoria de les Arts, 1989, vol. 22, n. ${ }^{\circ}$ 1, p. 284.

89 Escalona, Julio; Martín Viso, Ińaki. «Los palatia, puntos de centralización de rentas en la Meseta del Duero (siglos IX-XI)». En Vigil-Escalera, Alfonso; Bianchi, Giovanna. Horrea, Barns and Silos: Storage and Incomes in Early Medieval Europe. Bilbao: Universidad del País Vasco, 2013, p. 115.

90 Para Cosmen, este tipo de alusiones se refieren «al efecto general que produjo la obra cuando fue realizada de forma admirable», lo que corroboraría un aspecto cuidado: Cosmen, "Noticias sobre la reconstrucción», p. 604.

91 Monasterio fundado en el siglo x con gran tradición diplomática: Yáńez, María del Pilar. El monasterio de Santiago de León. León-Barcelona: Centro de Estudios e Investigación «San Isidoro»-Institución Milá y Fontanals, CSIC, 1972.

92 Martín Viso, «Monasterios y redes sociales en el Bierzo altomedieval». Hispania: Revista Española de Historia, 2011, vol. 71, n. ${ }^{\circ} 237$, p. 36.

93 Carvajal, «Un modelo historiográfico», p. 39.

94 Estepa, Estructura social, pp. 199-215.

95 Martínez Sopena, "Aristocracia, monacato y reformas», pp. 74-75.

96 Pérez, «El control de lo sagrado», p. 804. 
presentes en los ejemplos analizados, pero sería posible que alguna otra cuestión vinculada a la situación material de la ciudad propiciase estas fundaciones. El hipotético estado de ruina en que se encontraba León se plasma en los ejemplos de Santa Cristina y de Santiago. La información emanada de las fuentes escritas no ha podido corroborarse a través de los restos arqueológicos, que no han detectado niveles de destrucción asociados a este momento ${ }^{97}$. Si bien es cierto que el pago de 150 sueldos para la restauración de Santiago puede evidenciar una cierta necesidad de reconstruir algunos edificios de la ciudad.

Aunque es posible que las incursiones musulmanas tuviesen cierta afectación sobre esta coyuntura, otros factores han de ser tenidos en cuenta. Durante las décadas finales del siglo x y comienzos del siglo XI, la monarquía asturleonesa atravesó una situación de crisis caracterizada, entre otros factores, por la sucesión de rebeliones aristocráticas ${ }^{98}$. Las élites leonesas aprovecharon estas circunstancias para defender sus propios intereses ${ }^{99}$, mediante «la apropiación por parte de los señores de una importante cuantía de bienes raíces que sus antecesores habían entregado a las instituciones monásticas a las que consideraban como parte de sus propios patrimonios familiares» ${ }^{100}$. En este contexto, es probable que la fundación de estos centros no respondiese únicamente a una necesidad de reconstruir una ciudad materialmente arruinada, sino más bien a territorializar unas áreas en disputa dentro de la capital. Para alcanzar este objetivo es lógico pensar que los promotores, pertenecientes a los grupos de poder y parentelas, utilizasen una herramienta conocida, como es la fundación de monasterios propios. El hecho de que los condes Munio Fernández y Ansur Díaz tomasen la determinación de establecer monasterios en los lugares donde estaban sus palacios pone de relieve la mayor importancia que los edificios religiosos tenían en detrimento de las obras civiles para el León de este periodo.

Por el contrario, no queda tan claro si detrás de estos procesos edilicios había una verdadera vocación de perdurar. Las fundaciones se englobaban dentro de las dinámicas de los monasterios familiares, en las que era común que varias generaciones de una misma parentela creasen sus propios cenobios, por lo que es posible que existiese un menor interés en instituir edificios que fuesen a mantenerse en pie durante un periodo dilatado de tiempo. A modo de ejemplo, Justa Muñoz fundó junto a su esposo Ansur el monasterio de San Román, pero terminó ejerciendo como domina en el cenobio de San Martín de Pereda, constituido por sus padres ${ }^{101}$. Además, San Juan Bautista, San Félix,

97 Gutiérrez, "Génesis del urbanismo», p. 58; Gutiérrez, José Avelino; Miguel, Fernando; Campomanes, Emilio; Muñoz, Fernando; García, Victorino. «Revisión arqueológica de las murallas de León (España)». En VV. AA. Fortificaçoes e Território na Península Ibérica e no Magreb (Séculos VI a XVI). Lisboa: Ediçoes Colibri, 2013, p. 315.

98 Carvajal, Álvaro. Bajo la máscara del regnum: la monarquía asturleonesa en León (854-1037). Madrid: CSIC, 2017, pp. 86-90.

99 Este proceso se conoce como alfetena: Martínez Sopena, Pascual. «Reyes, condes e infanzones. Aristocracia y alfetena en el Reino de León». En VV. AA. Ante el Milenario del reinado de Sancho el Mayor, un rey navarro para España y Europa. Pamplona: Institución Príncipe de Viana, 2004, pp. 133-134.

100 García de Cortázar, José Ángel. «Reyes y abades en el Reino de León (años 919 a 1157)». En VV. AA. Monarquía y sociedad en el Reino de León. De Alfonso III a Alfonso VII. León: Centro de Estudios e Investigación «San Isidoro», 2007, p. 211.

101 Pérez, Mariel. «Aristocracia, monasterios particulares y poder episcopal en el Reino de León: Los monasterios de los Flaínez». Trabajo y Comunicaciones, 2013, vol. 39, p. 172. 
San Vicente, Santa María o San Román pasaron a formar parte del patrimonio de la catedral en fechas próximas a su fundación ${ }^{102}$. A partir de este punto, no resulta sencillo seguir la pista de estos centros, que sufrieron una progresiva pérdida de relevancia que culminó cuando ninguno apareció convertido en parroquia en el siglo XIII ${ }^{103}$ y tan solo San Miguel fue mencionado en el Becerro, que recoge datos de mediados del siglo XIII ${ }^{104}$.

Pese a que no se puede rastrear el momento de desaparición material de estos monasterios, sí se puede hablar de un cambio en las tendencias edilicias que habían conducido a su construcción. El reinado de Fernando I y Sancha supuso un progresivo reforzamiento del poder regio ${ }^{105}$ que tuvo su reflejo en las ciudades y "condicionó la evolución del espacio urbano» ${ }^{106}$. Para el contexto leonés, aunque el crecimiento orgánico de la ciudad y su carácter agrario no desaparecieron, se produjo una transformación hacia una mayor planificación ${ }^{107}$. La presencia regia se plasmó materialmente con la promoción de San Isidoro y culminó con el traslado de los restos del santo en $1063^{108}$. La monumentalidad alcanzada por este edificio no solo implicó la aparición de un nuevo foco de poder, sino también la creación de un hito en el paisaje que probablemente minimizó el empaque visual que estos monasterios propios pudieron tener ${ }^{109}$. En este sentido, resulta llamativo que tan solo tres de los ejemplos - San Pedro y San Pablo, Santa María y San Román- fueran edificados a partir de la década de los treinta, momento en el que se estaba produciendo este robustecimiento del poder regio.

El cese de este tipo de iniciativas también estuvo propiciado por dinámicas a mayor escala, que condicionaron la pérdida de vigencia del fenómeno de los monasterios propios. Se trata principalmente de la permeabilización de los preceptos del concilio de Coyanza — que estipulaban que la fundación de iglesias y monasterios debía estar sujeta a la consagración de un obispo y sometida a catedrales o grandes centros monásticos- y de la llegada de la influencia benedictina, acusada durante la segunda mitad del siglo $\mathrm{XI}^{110}$. A todo esto, debe ańadirse la disponibilidad de una mayor cantidad de recursos

102 Estepa, Estructura social, pp. 203-205.

103 Estepa, Estructura social, pp. 203-205.

104 Sanct Miguell. De Sanct Clodio. Del deanadgo. Su ubicación extramuros podría corroborar que se trata de la misma institución, pero no permite asegurar la conservación del edificio fundado por Félix. Fernández Flórez, José Antonio. «El 'Becerro de presentaciones'. Códice 13 del Archivo de la Catedral de León. Un parroquial leonés de los siglos XIII-XV». En VV.AA. León y su historia. Miscelánea histórica V. León: Centro de Estudios e Investigación «San Isidoro», 1984, p. 358.

105 Martínez Sopena, «Reyes y nobles», p. 184.

106 Monsalvo Antón, José María. «Espacios y poderes en la ciudad medieval. Impresiones a partir de cuatro casos: León, Burgos, Ávila y Salamanca». En Iglesia Duarte, Ignacio de la; Martín Rodríguez, JoséLuis. Los espacios del poder en la España medieval: XII Semana de Estudios Medievales. Logrońo: Instituto de Estudios Riojanos, 2002, p. 106.

107 Gutiérrez; Miguel, "Génesis del urbanismo», p. 54.

108 Martin, Therese. "Recasting the concept of the "Pilgrimage Church»: the case of San Isidoro de León». La Crónica, 2008, vol. 36, 2, pp. 167-168.

109 Cabe destacar que en la década de los sesenta se inició la restauración de la Catedral de Santa María de Regla, otro hito destacable del paisaje leonés. VV. AA. Enciclopedia del Románico, p. 591.

110 Martínez Sopena, Pascual. «La Reforma de la Iglesia y las comunidades campesinas: León y Castilla en el siglo XI». En Dierkens, Alain; Schroeder, Nicolas; Wilkin, Alexis (Dir.). Penser la paysannerie médiévale, un défi impossible? París: Éditions de la Sorbonne, 2017, pp. 347-361 
económicos, que se invertían en la construcción de los edificios románicos ${ }^{111}$ y la instauración progresiva de un «nuevo modelo de patronato, formalmente más respetuoso con las instituciones» ${ }^{12}$, que limitaba la intervención directa de los fundadores en la vida monástica.

\section{HACIA UNA SÍNTESIS DE LOS PROCESOS CONSTRUCTIVOS DE LOS MONASTERIOS LEONESES}

Como se ha podido apreciar, existió cierto dinamismo en los procesos de construcción de León durante la primera mitad del siglo xI. Este no solo se tradujo en la aparición de nuevos edificios, como en los casos de los monasterios de San Miguel, San Félix, San Vicente, San Pedro y San Pablo o Santa María, o la casa de Celanova; sino también en la transformación de estructuras previas, como se ha teorizado para los ejemplos de San Juan Bautista y San Román. Todos estos elementos edilicios convivieron con otros que se encontraban en total o parcial estado de ruina -el monasterio de Santa Cristina y el de Santiago, respectivamente-, dotando a la ciudad de un aspecto característico, donde edificios de monumentalidad apenas cognoscible compartían el espacio con restos del pasado y múltiples solares vacíos. Los promotores de estas obras se otorgaron a sí mismos un papel fundamental en el proceso de fundación, representándose como los «constructores» en los documentos y poniendo de manifiesto la significación social que existía tras el acto de levantar una edificación de cierta envergadura. En este sentido, es necesario destacar también la importancia simbólica que tenían los centros religiosos en detrimento de los laicos, tal como muestran las conversiones de palacios en monasterios.

Las iniciativas tras estas construcciones implicaban a un individuo o a una pareja que, aunque tenían vinculación con las parentelas magnaticias, llevaban a cabo estas obras de manera autónoma, sin que se pudiera percibir una planificación a mayor escala. Pese a que servían como resguardo de una parte del patrimonio del linaje, es probable que las inversiones se limitasen a las capacidades adquisitivas de la persona o personas directamente comprometidas. Esto repercutiría en la materialidad del propio edificio, ya que no era posible alcanzar las cotas de monumentalidad de obras auspiciadas por los monarcas, como San Salvador, que contaron con mayores recursos y proyección. Por tanto, aunque no se conserven restos que puedan adscribirse a estos cenobios, ni que aclararen como eran el resto de los elementos del entorno, es plausible plantear que cualquier carácter destacable que pudieran tener, quedaría relegado a un segundo plano después de la creación de San Isidoro y de la restauración de la catedral.

La rápida desvinculación de los fundadores y sus obras mediante su donación a instituciones más relevantes, como la sede catedralicia, se vincula con las dinámicas de los

111 García de Cortázar, José Ángel. «Los monasterios del reino de León y Castilla a mediados del siglo XI. Un ejemplo de selección de las especies». En García de Cortázar, José Ángel; Teja, Ramón. Monjes y monasterios hispanos en la Alta Edad Media. Aguilar de Campoo: Fundación Santa María la Real, 2006, p. 259.

112 Martínez Sopena, Pascual. «Fundaciones monásticas y nobleza en los reinos de Castilla y León en la época románica». García de Cortázar, José Ángel (Coord.). Monasterios románicos y producción artística. Aguilar de Campoo: Fundación Santa María la Real, 2003, p. 37. 
monasterios particulares, pero también con el hecho de que existían en la ciudad de León poderes más afianzados, que ejercían un control más efectivo del espacio. En este sentido, hacia la segunda mitad del siglo XI cesaron los conflictos por la titularidad de los solares urbanos — como los que se han visto para los casos de San Miguel y San Román—, así como las iniciativas nobiliarias de creación de nuevos edificios representativos. Esto lleva a plantearse si existió un deseo de perdurar detrás de la construcción de los centros estudiados, ya que desde el momento en el que pierden su papel como herramientas para la territorialización de la capital regia, fueron desapareciendo de manera progresiva.

Para concluir, los elementos expuestos no permiten avalar la aparición del fenómeno de la petrificación de la riqueza en la ciudad de León a comienzos del siglo xI. Aún no estaban del todo establecidos algunos de los preceptos clave del proceso petrificador, como la extensión de las construcciones de calidad y el empleo de ciclos productivos complejos. Estos se verían impulsados por ciertos procesos que comenzaron a gestarse durante esta cronología, como el reforzamiento del poder regio, la permeabilización de la reforma benedictina o el aumento de la riqueza. No obstante, se observa una más que probable extensión del empleo de materiales duraderos, como en el caso de la piedra, utilizada mediante técnicas de mampostería y reaprovechamiento de los lienzos murarios. Por lo tanto, probablemente se trata de un antecedente que condicionó la evolución del proceso de petrificación en la ciudad en los siglos posteriores.

\section{REFERENCIAS BIBLIOGRÁFICAS}

Álvarez Maurín, María del Pilar. Diplomática asturleonesa. Terminología toponímica. León: Universidad de León, 1994.

Bango Torviso, Isidro G. «La vieja liturgia hispana y la interpretación del templo prerrománico». En VII Semana de Estudios Medievales. Logroño: Instituto de Estudios Riojanos, 1997, pp. 61-120.

Carriedo Tejedo, Manuel. «Dos fraudes sincrónicos al monasterio de Celanova (en León y en Galicia) a comienzos del siglo XI». Rudesindus, 2008, vol. 4, pp. 43-62.

Carvajal, Álvaro. «Un modelo (historiográfico) para armar». En García-Fernández, Miguel; Cernadas Martínez, Silvia (Coord.). Reinas e infantas en los reinos medievales ibéricos. Santiago de Compostela: Universidad de Santiago de Compostela, 2018, pp. 29-50.

Carvajal, Álvaro. Bajo la máscara del regnum: la monarquía asturleonesa en León (854-1037). Madrid: CSIC, 2017.

Cavero Domínguez, Gregoria. «Organización eclesiástica de las civitates episcopales de León y Astorga (siglo x)». En VV. AA. Iglesia y ciudad. Espacio y poder (siglos VIII-XIII). Oviedo-León: Universidad de Oviedo-Universidad de León-Instituto de Estudios Medievales, 2011, pp. 67-101.

Cosmen, María Concepción. «Noticias sobre la reconstrucción arquitectónica en la Diócesis de León durante el siglo X». En Delisau Jorge, María de los Ángeles; Rodríguez Padilla, Marta; Pueyo Abril, Javier (Coords). La multiculturalidad en las Artes y en la Arquitectura: XVI Congreso Nacional de Historia del Arte. Vol. 1. Las Palmas de Gran Canaria: Anroart Ediciones, 2006, pp. 599-607. 
Davies, Wendy. «Notions of Wealth in The Charters of Ninth- and Tenth-Century Christian Iberia». En Devroey, Jean-Pierre; Feller, Laurent; Le Jan, Régine (Dir.). Les élites et la richesse au Haut Moyen Age. Turnhout: Brepols, 2011, pp. 265-284.

Escalona, Julio; Martín Viso, Ińaki. «Los palatia, puntos de centralización de rentas en la Meseta del Duero (siglos IX-XI)». En Vigil-Escalera, Alfonso; Bianchi, Giovanna. Horrea, Barns and Silos: Storage and Incomes in Early Medieval Europe. Bilbao: Universidad del País Vasco, 2013, pp. 103-126.

Estepa, Carlos. Estructura social de la ciudad de León (siglos XI-XIII). León: Centro de Estudios e Investigación «San Isidoro», 1977, pp. 117-119.

Feller, Laurent. «Introduction: Formes et fonctions de la richesse des élites au Haut Moyen Âge». En Devroey, Jean-Pierre; Feller, Laurent; Le Jan, Régine (Dir.). Les élites et la richesse au Haut Moyen Age. Turnhout: Brepols, 2011, pp. 5-30.

Fernández Flórez, José Antonio. «El 'Becerro de presentaciones'. Códice 13 del Archivo de la Catedral de León. Un parroquial leonés de los siglos XIII-XV». En VV. AA. León y su historia. Miscelánea histórica V. León: Centro de Estudios e Investigación «San Isidoro», 1984, pp. 263-565.

Gallart, Pascual. «El ritual de la dedicación de la iglesia en los pontificales medievales y su ciclo icónico». IMAGO Revista de Emblemática y Cultura Visual, 2013, vol. 5, pp. 79-89.

García Álvarez, Manuel Rubén. "La infanta Fronilde, peregrina a Compostela». Compostellanum: revista de la Archidiócesis de Santiago de Compostela, 1964, vol. 9, n. ${ }^{\circ}$ 2, pp. 173-195.

García de Cortázar, José Ángel; Peña Bocos, Esther. «El Palatium, símbolo y centro de poder, en los reinos de Navarra y Castilla en los siglos x a XII». Mayurqa: revista del Departament de Ciències Històriques i Teoria de les Arts, 1989, 22, 1, pp. 281-296.

García de Cortázar, José Ángel. «Los monasterios del reino de León y Castilla a mediados del siglo XI. Un ejemplo de selección de las especies». En García de Cortázar, José Ángel; Teja, Ramón. Monjes y monasterios hispanos en la Alta Edad Media. Aguilar de Campoo: Fundación Santa María la Real, 2006, pp. 255-288.

García de Cortázar, José Ángel. «Monasterios hispanos en torno al año mil: función social y observancia regular». En VV. AA. Ante el milenario del reinado de Sancho el Mayor: un rey navarro para España y Europa. Pamplona: Gobierno de Navarra, 2003, pp. 213-270.

García de Cortázar, José Ángel. «Reyes y abades en el Reino de León (años 919 a 1157)». En VV. AA. Monarquía y sociedad en el Reino de León. De Alfonso III a Alfonso VII. León: Centro de Estudios e Investigación «San Isidoro», 2007, pp. 201-263.

González, Raúl. Élites urbanas y relaciones de poder en Oviedo, León y Astorga durante la Edad Media (siglos IX-XIII). Universidad de Oviedo, 2017. Tesis doctoral.

Gutiérrez, José Avelino y Miguel, Fernando. «Génesis del urbanismo en la ciudad de León y su transformación en la Edad Media». Codex aquilarensis: Cuadernos de investigación del Monasterio de Santa María la Real, 1999, 15, pp. 43-90.

Gutiérrez, José Avelino. «Las fuentes arqueológicas informadoras del espacio urbano medieval: la ciudad de León como ejemplo». En Solórzano Telechea, Jesús Ángel; Arízaga Bolumburu, Beatriz (Coords.) El espacio urbano en la Europa Medieval. Nájera. Encuentros internacionales del Medievo. Logrońo: Instituto de Estudios Riojanos, 2006, pp. 77-145.

Gutiérrez, José Avelino; Miguel, Fernando; Campomanes, Emilio; Muñoz, Fernando; García, Victorino. «Revisión arqueológica de las murallas de León (España)». En VV. AA. Fortiffcaçoes e Território na Península Ibérica e no Magreb (Séculos VI a XVI). Lisboa: Ediçoes Colibri, 2013, pp. 314-327. 
LA REPRESENTACIÓN DOCUMENTAL DE UNA REALIDAD MATERIAL DESAPARECIDA:

Herrero Jiménez, Mauricio. Colección documental del Archivo de la Catedral de León: Obituarios Medievales. León: Centro de Estudios e Investigación «San Isidoro», 1994.

Martín Viso, Ińaki. «Monasterios y poder aristocrático». Brocar, 1996, vol. 20, pp. 91-133.

Martín Viso, Iñaki. «Monasterios y redes sociales en el Bierzo altomedieval». Hispania: Revista Española de Historia, 2011, vol. 71, n. ${ }^{\circ}$ 237, pp. 9-38.

Martin, Therese. «Exceptions and Assumptions: Women in Medieval Art History». En Martin, Therese (Ed.). Reassessing the Roles of Women as 'Makers' of Medieval Art and Architecture. Leiden-Boston: Brill, 2012, pp. 1-33.

Martin, Therese. «Recasting the concept of the «Pilgrimage Church»: the case of San Isidoro de León». La Crónica, 2008, vol. 36, 2, pp. 165-189.

Martin, Therese. «The margin to act: a framework of investigation for women's (and men's) medieval art-making». Journal of Medieval History, 2016, vol. 42, no 1, pp. 1-25.

Martin, Therese. "Chronicling the Iberian Palace: written sources and the meaning of medieval Christian rulers' residences». Journal of Medieval Iberian Studies, 2010, vol. 2, n. ${ }^{\circ}$ 1, pp. 109-139.

Martínez Sopena, «Reyes y nobles en León (ca. 860-1160)». En VV. AA. Monarquía y sociedad en el Reino de León. De Alfonso III a Alfonso VII. León: Centro de Estudios e Investigación «San Isidoro", 2007, pp. 149-200.

Martínez Sopena, Pascual. «Aristocracias, monacato y reformas en los siglos XI y XII». VV. AA. El monacato en los reinos de León y Castilla (siglos VII-XIII). Ávila: Fundación Sánchez-Albornoz, 2007, pp. 67-100.

Martínez Sopena, Pascual. «Fundaciones monásticas y nobleza en los reinos de Castilla y León en la época románica». García de Cortázar, José Ángel (Coord.). Monasterios románicos y producción artística. Aguilar de Campoo: Fundación Santa María la Real, 2003, pp. 35-62.

Martínez Sopena, Pascual. «La Reforma de la Iglesia y las comunidades campesinas: León y Castilla en el siglo XI». En Dierkens, Alain; Schroeder, Nicolas; Wilkin, Alexis (Dir.). Penser la paysannerie médiévale, un défi impossible? París: Éditions de la Sorbonne, 2017, pp. 347-361.

Martínez Sopena, Pascual. «Monasterios particulares, nobleza y reforma eclesiástica en León entre los siglos XI y XII». En Ladero Quesada, Miguel Ángel; Álvarez Palenzuela, Vicente Ángel; Valdeón Baruque, Julio (Coord.). Estudios de Historia Medieval. Homenaje a Luis Suárez. Valladolid: Universidad de Valladolid, 1991, pp. 323-331.

Martínez Sopena, Pascual. «Prolis Flainiz. Las relaciones familiares en la nobleza de León». Studia Zamoranensia, 2018, vol. XVII, pp. 69-102.

Martínez Sopena, Pascual. «Reyes, condes e infanzones. Aristocracia y alfetena en el Reino de León». En VV. AA. Ante el Milenario del reinado de Sancho el Mayor, un rey navarro para España y Europa. Pamplona: Institución Príncipe de Viana, 2004, pp. 109-154.

Martínez Sopena, Pascual. La Tierra de Campos occidental: poblamiento, poder y comunidad del siglo X al XIII. Valladolid: Institución Cultural Simancas, 1985.

Monsalvo Antón, José María. «Espacios y poderes en la ciudad medieval. Impresiones a partir de cuatro casos: León, Burgos, Ávila y Salamanca». En Iglesia Duarte, Ignacio de la; Martín Rodríguez, José-Luis. Los espacios del poder en la España medieval: XII Semana de Estudios Medievales. Logroño: Instituto de Estudios Riojanos, 2002, pp. 97-147.

Navarro Baena, Alberto. «La memoria regia a través de los obituarios leoneses». En Arias Guillén, Fernando y Martínez Sopena, Pascual (cords.). Los espacios del rey. Poder y territorio en las monarquias hispánicas (siglos XII-XIV). Bilbao: Universidad del País Vasco, 2018, pp. 397-418.

Orlandis, José. «Los monasterios familiares en España durante la Alta Edad Media». Anuario de Historia del Derecho Español, 1956, vol. 26, pp. 5-46. 
Pérez, Mariel. «Aristocracia, monasterios particulares y poder episcopal en el Reino de León: Los monasterios de los Flaínez». Trabajo y Comunicaciones, 2013, vol. 39, pp. 165-189.

Pérez, Mariel. «El control de lo sagrado como instrumento de poder: los monasterios particulares de la aristocracia altomedieval leonesa». Anuario de Estudios Medievales, julio-diciembre 2012, vol. 42/2, pp. 799-822.

Pérez, Mariel. «Proprietary churches, episcopal authority and social relationships in the diocese of León (eleventh-twelfth centuries)». Journal of Medieval Iberian Studies, 2018, vol. 10, n. 2, pp. 195-212.

Pérez, Maurilio (Ed.). Lexicon Latinatis Medii Aevi Regni Legionis (s. VIII-1230). Imperfectvm. Turnhout: Brepols, 2010.

Posadilla, Juan de Dios. Episcopologio legionense: biografía de los obispos de León. Tomo I. León: Imp. de Maximino A. Miñón, 1899.

Risco, Manuel. Iglesias de León y monasterios antiguos de la misma ciudad. Madrid: En la oficina de Don Blas Román, 1792.

Ruiz Asencio, José Manuel. Colección documental del Archivo de la Catedral de León (775-1230). Vol. III (986-1031). León: Centro de Estudios e Investigación «San Isidoro», 1987.

Ruiz Asencio, José Manuel. Colección documental del Archivo de la Catedral de León (775-1230). Vol. IV (1032-1109). León: Centro de Estudios e Investigación «San Isidoro», 1989.

Sánchez-Albornoz, Claudio. Una ciudad de la España cristiana hace mil años. Estampas de la vida en León. Madrid: Rialp, 1982.

Santos Coco, Francisco. Historia Silense. Madrid: Sucesores de Rivadeneyra, 1921.

VV. AA. Enciclopedia del Románico en Castilla y León: León. Aguilar de Campoo: Fundación Santa María la Real, 2002.

Yáneez, María del Pilar. El monasterio de Santiago de León. León-Barcelona: Centro de Estudios e Investigación «San Isidoro»-Institución Milá y Fontanals, CSIC, 1972. 